\title{
Editorial: Leukocyte Trafficking in Homeostasis and Disease
}

\author{
Joaquin Teixidó ${ }^{1 *}$, Andres Hidalgo ${ }^{2,3}$ and Susanna Fagerholm ${ }^{4}$ \\ ${ }^{1}$ Department of Molecular Biomedicine, Centro de Investigaciones Biológicas (CSIC), Madrid, Spain, ${ }^{2}$ Department of Cell \\ and Developmental Biology, Centro Nacional de Investigaciones Cardiovasculares, Madrid, Spain, ${ }^{3}$ Institute for \\ Cardiovascular Prevention, Ludwig-Maximilians University, Munich, Germany, ${ }^{4}$ Research Program of Molecular and \\ Integrative Biosciences, Faculty of Bio- and Environmental Sciences, University of Helsinki, Helsinki, Finland
}

Keywords: leukocyte, traffic, homeostasis, inflammation, cancer

\section{Editorial on the Research Topic}

\section{Leukocyte Trafficking in Homeostasis and Disease}

Leukocytes move avidly through the body. While this is classically associated with immune responses, leukocyte trafficking is just as prominent during steady-state conditions as they leave the bone marrow (BM), home back to tissues for elimination, or traffic through secondary lymphoid organs (1). However, immune cell trafficking becomes uncontrolled during inflammatory pathologies $(2,3)$, and in the homing of hematologic tumor cells to BM and lymph nodes. Diapedesis of immune cells and blood cancer cells across endothelium is facilitated by chemokines and adhesion molecules, which act in concert in tightly regulated directional motility (1-6).

The Research Topic on "Leukocyte Trafficking in Homeostasis and Disease" covers several reviews providing an up-to-date view of different molecular and cellular players that regulate key trafficking processes during cell differentiation, immune responses and lymphocyte recirculation, as well as in inflammatory pathologies and in hematological malignancies.

\section{OPEN ACCESS}

Edited and reviewed by: Pietro Ghezzi,

Brighton and Sussex Medical School, United Kingdom

*Correspondence: Joaquin Teixido joaquint@cib.csic.es

Specialty section: This article was submitted to Inflammation,

a section of the journal

Frontiers in Immunology

Received: 10 September 2019 Accepted: 15 October 2019

Published: 01 November 2019

Citation: Teixidó J, Hidalgo A and Fagerholm S (2019) Editorial: Leukocyte Trafficking in Homeostasis and Disease. Front. Immunol. 10:2560. doi: 10.3389/fimmu.2019.02560

\section{NEUTROPHIL TRAFFICKING}

Integrins are key adhesion receptors controlling leukocyte trafficking. In their review, Fagerholm et al. describe the critical roles of $\beta 2$ integrins in leukocyte trafficking and other leukocyte functions that are dependent on cell adhesion (7). The importance of $\beta 2$ integrins for immune function is shown by rare genetic disorders (Leukocyte adhesion deficiencies, or LAD) that affect their expression (LAD-I) or function (LAD-III, caused by mutations in the integrin regulator, kindlin3) $(8,9)$. However, $\beta 2$ integrins are also associated with many immune suppressive functions. For example, they can inhibit tissue migration of dendritic cells, and also suppress cytokine responses in myeloid cells (10-12). Because of these various roles in immunity, $\beta 2$ integrin dysfunction can contribute to the development of both immunodeficiency diseases and inflammatory diseases.

The classical leukocyte recruitment cascade consisting of leukocyte capture, rolling, arrest, firm adhesion, crawling and finally, transmigration through the endothelium (2), is widely accepted as the way leukocytes are recruited into tissues. Maas et al. describe the variations in the trafficking rules that neutrophils use to enter different tissues, focusing on lung, liver, kidney and aorta. These rules are distinct in different organs and tissues, and there appears to be significant redundancy in the system (chemokines, etc.), which may explain why it is so difficult to target leukocyte recruitment successfully in the clinic.

Focusing on the migratory dynamics of neutrophils, Morikis and Simon summarize an extensive body of literature suggesting that biomechanical signals at the original site of interactions between leukocytes and the activated endothelium critically regulate leukocyte adhesion and polarization. The extensive, but poorly characterized interplay between multiple types of receptors (selectins, glycoproteins, integrins, or calcium channels) in these regions is discussed to be critical at these 
early stages of the recruitment cascade. With the description of how protein modules in integrins and cytoskeleton reorganize, and the relevance of these events in controlling neutrophil migration, Morikis and Simon provide an exciting review of the intricate biomechanics of immunity.

Neutrophils must cross multiple barriers in the body to reach the areas where they will perform their immune tasks (13). An underappreciated aspect of this migration is how the cell adapts to the constraints imposed by each barrier, be it endothelial, matricial, or interstitial. Salvermoser et al. discuss how neutrophils adapt to the varying environments, and in particular focus on adaptations of nucleus, which is the stiffest cellular organelle. As thoroughly reviewed by the authors, nuclear architecture and deformability are key features that allow the swift and efficient migration of neutrophils through multiple environments.

Leukocytes not only travel into peripheral tissues, but can interestingly also regulate BM hematopoietic stem cells (HSC) (14). The review by Lucas describes the HSC niche, its components and its regulation by leukocytes and by leukocyte trafficking. HSCs give rise to leukocyte subtypes (including neutrophils), which feed back to the HSC niche, regulating both HSC number and function. This crosstalk may function as a biological rheostat during inflammation and in different disease states, and this feedback system allows the BM to monitor the periphery and to adjust leukocyte output according to peripheral needs, although many of the finer details still remain to be elucidated.

\section{PLATELETS IN LEUKOCYTE RECRUITMENT AND RESOLUTION OF INFLAMMATION}

Current research has expanded the appreciation of platelets beyond their contribution to primary hemostasis, indicating that they also actively participate in leukocyte recruitment, especially neutrophils, and in the regulation of the host defense in response to exogenous injuries (15). Platelets physically interact with different leukocyte subsets during inflammatory processes (16), which hold extensive implications for the leukocyte recruitment into peripheral tissues and for the regulation of leukocyte cell autonomous functions, including the formation and liberation of neutrophil extracellular traps. In addition, platelets have also been implicated in the resolution of inflammation (17). The review by Rossaint et al. focuses on the role of platelets in leukocyte recruitment during the initiation of the host defense, and also discusses their participation in the resolution process after acute inflammation.

\section{MONOCYTE AND MACROPHAGE TRAFFICKING}

Teh et al. describe recent advances in the field of monocyte trafficking. Monocytes are highly plastic cells which can perform effector functions in their own right, or traffic into tissues and differentiate into various monocyte-derived cell types, both during homeostasis and in different diseases (18). Major advances in understanding the role of monocytes and monocyte-derived cells were possible in recent years due to development of imaging techniques, but the authors point out that these cells are still challenging to investigate due to their plasticity.

In an original research paper included in this Topic, Cui et al. studied the role of the $\alpha \mathrm{L} \beta 2$ and $\alpha \mathrm{D} \beta 2$ integrins in macrophage migration in tissues. They show that $3 \mathrm{D}$ amoeboid macrophage migration is inhibited by high $\beta 2$ integrin expression, whilst a moderate expression of the integrin promotes it.

\section{CATECHOLAMINES, GLUCOCORTICOIDS AND SCAVENGER RECEPTORS}

Ince et al. provide an exhaustive overview of the dynamics of multiple leukocyte subsets with particular emphasis on the molecular cues guiding their trafficking patterns during baseline or inflammatory conditions. The first of these cues are catecholamines, which are neurotransmitters produced by the adrenal gland, sympathetic nerves and even leukocytes themselves. Recent studies established important roles for catecholamines in regulating the expression of adhesion molecules and chemoattractants by endothelial cells, but also through direct actions on leukocytes $(19,20)$. A second class of cues is the glucocorticoids, a type of steroid hormones produced by the adrenal gland. These hormones influence many aspects of leukocyte behavior by generally reducing their adhesive capacity $(21,22)$. This can induce, for example, potent demargination of certain leukocyte types by attenuating interactions with vascular cells (23). Because the presence of both signals display potent circadian patterns, the review also discusses how these signals contribute to diurnal rhythms in leukocyte trafficking.

The review by Patten and Shetty describes roles of scavenger receptors expressed on endothelial cells (24), which regulate the leukocyte trafficking. However, the roles of these receptors in leukocyte migration are less well-understood than those of other traditional adhesion receptors.

\section{HEMATOLOGIC TUMOR CELL TRAFFICKING}

The trafficking of hematologic tumor cells is facilitated by adhesion molecules and chemokines, a process that contributes to progression of hematologic malignancies $(4,6)$. A common feature of multiple myeloma, chronic lymphocytic leukemia and acute lymphoblastic leukemia is the homing and lodging of blood cancer cells in the BM, which favors their growth and survival. The $\alpha 4 \beta 1$ integrin and the chemokine receptor CXCR 4 are key molecules for cell trafficking into and out of the BM in these hematologic neoplasias $(25,26)$. Redondo-Muñoz et al. review the molecular players that regulate the trafficking of neoplastic cells during development and progression of these hematologic malignancies.

\section{AUTHOR CONTRIBUTIONS}

All authors listed have made a substantial, direct and intellectual contribution to the work, and approved it for publication. 


\section{REFERENCES}

1. Vestweber D. How leukocytes cross the vascular endothelium. Nat Rev Immunol. (2015) 15:692-704. doi: 10.1038/nri3908

2. Ley K, Laudanna C, Cybulsky MI, Nourshargh S. Getting to the site of inflammation: the leukocyte adhesion cascade updated. Nat Rev Immunol. (2007) 7:678-89. doi: 10.1038/nri2156

3. Nourshargh S, Alon R. Leukocyte migration into inflamed tissues. Immunity. (2014) 41:694-707. doi: 10.1016/j.immuni.2014.10.008

4. Chow MT, Luster AD. Chemokines in cancer. Cancer Immunol Res. (2014) 2:1125-31. doi: 10.1158/2326-6066.CIR-14-0160

5. Sokeland G, Schumacher U. The functional role of integrins during intraand extravasation within the metastatic cascade. Mol Cancer. (2019) 18:12. doi: 10.1186/s12943-018-0937-3

6. Hamidi H, Ivaska J. Every step of the way: integrins in cancer progression and metastasis. Nat Rev Cancer. (2018) 18:533-48. doi: 10.1038/s41568-018-0038-z

7. Alon R, Feigelson SW. Chemokine-triggered leukocyte arrest: force-regulated bi-directional integrin activation in quantal adhesive contacts. Curr Opin Cell Biol. (2012) 24:670-6. doi: 10.1016/j.ceb.2012.06.001

8. Badolato R. Defects of leukocyte migration in primary immunodeficiencies. Eur J Immunol. (2013) 43:1436-40. doi: 10.1002/eji.201243155

9. Rognoni E, Ruppert R, Fassler R. The kindlin family: functions, signaling properties and implications for human disease. J Cell Sci. (2016) 129:17-27. doi: $10.1242 /$ jcs. 161190

10. Wang L, Gordon RA, Huynh L, Su X, Park Min KH, Han J, et al. Indirect inhibition of Toll-like receptor and type I interferon responses by ITAM-coupled receptors and integrins. Immunity. (2010) 32:518-30. doi: 10.1016/j.immuni.2010.03.014

11. Han C, Jin J, Xu S, Liu H, Li N, Cao X. Integrin CD11b negatively regulates TLR-triggered inflammatory responses by activating Syk and promoting degradation of MyD88 and TRIF via Cbl-b. Nat Immunol. (2010) 11:734-42. doi: 10.1038/ni.1908

12. Morrison VL, James MJ, Grzes K, Cook P, Glass DG, Savinko T, et al. Loss of beta2-integrin-mediated cytoskeletal linkage reprogrammes dendritic cells to a mature migratory phenotype. Nat Commun. (2014) 5:5359. doi: 10.1038/ncomms6359

13. Nicolas-Avila JA, Adrover JM, Hidalgo A. Neutrophils in homeostasis, immunity, and cancer. Immunity. (2017) 46:15-28. doi: 10.1016/j.immuni.2016.12.012

14. Cossio 1, Lucas D, Hidalgo A. Neutrophils as regulators of the hematopoietic niche. Blood. (2019) 133:2140-8. doi: 10.1182/blood-2018-10-844571

15. Li JL, Zarbock A, Hidalgo A. Platelets as autonomous drones for hemostatic and immune surveillance. J Exp Med. (2017) 214:2193. doi: 10.1084/jem.20170879

16. Rossaint J, Zarbock A. Platelets in leucocyte recruitment and function. Cardiovasc Res. (2015) 107:386-95. doi: 10.1093/cvr/cvv048
17. Ortiz-Munoz G, Mallavia B, Bins A, Headley M, Krummel MF, Looney MR. Aspirin-triggered 15-epi-lipoxin A4 regulates neutrophil-platelet aggregation and attenuates acute lung injury in mice. Blood. (2014) 124:2625-34. doi: 10.1182/blood-2014-03-562876

18. Jakubzick CV, Randolph GJ, Henson PM. Monocyte differentiation and antigen-presenting functions. Nat Rev Immunol. (2017) 17:349-62. doi: $10.1038 /$ nri.2017.28

19. Mendez-Ferrer S, Lucas D, Battista M, Frenette PS. Haematopoietic stem cell release is regulated by circadian oscillations. Nature. (2008) 452:442-7. doi: 10.1038/nature06685

20. Scheiermann C, Kunisaki Y, Lucas D, Chow A, Jang JE, Zhang D, et al. Adrenergic nerves govern circadian leukocyte recruitment to tissues. Immunity. (2012) 37:290-301. doi: 10.1016/j.immuni.2012.05.021

21. Shimba A, Cui G, Tani-Ichi S, Ogawa M, Abe S, Okazaki F, et al. Glucocorticoids drive diurnal oscillations in T cell distribution and responses by inducing interleukin-7 receptor and CXCR4. Immunity. (2018) 48:28698.e6. doi: 10.1016/j.immuni.2018.01.004

22. Besedovsky L, Linz B, Born J, Lange T. Mineralocorticoid receptor signaling reduces numbers of circulating human naive $\mathrm{T}$ cells and increases their CD62L, CCR7, and CXCR4 expression. Eur J Immunol. (2014) 44:1759-69. doi: 10.1002/eji.201344265

23. Schaffner and J. Fehr. Granulocyte demargination by epinephrine in evaluation of hypersplenic states. Scand J Haematol. (1981) 27:225-30. doi: 10.1111/j.1600-0609.1981.tb00477.x

24. Canton J, Neculai D, Grinstein S. Scavenger receptors in homeostasis and immunity. Nat Rev Immunol. (2013) 13:621-34. doi: 10.1038/nri3515

25. Martinez-Moreno M, Leiva M, Aguilera-Montilla N, Sevilla-Movilla S, Isern de Val S, Arellano-Sanchez N, et al. In vivo adhesion of malignant B cells to bone marrow microvasculature is regulated by alpha4betal cytoplasmicbinding proteins. Leukemia. (2016) 30:861-72. doi: 10.1038/leu.20 15.332

26. Passaro D, Irigoyen M, Catherinet C, Gachet SC, Da Costa De Jesus C, Lasgi C, et al. CXCR4 is required for leukemia-initiating cell activity in $\mathrm{T}$ cell acute lymphoblastic leukemia. Cancer Cell. (2015) 27:769-79. doi: 10.1016/j.ccell.2015.05.003

Conflict of Interest: The authors declare that the research was conducted in the absence of any commercial or financial relationships that could be construed as a potential conflict of interest.

Copyright (c) 2019 Teixidó, Hidalgo and Fagerholm. This is an open-access article distributed under the terms of the Creative Commons Attribution License (CC BY). The use, distribution or reproduction in other forums is permitted, provided the original author(s) and the copyright owner(s) are credited and that the original publication in this journal is cited, in accordance with accepted academic practice. No use, distribution or reproduction is permitted which does not comply with these terms. 